\title{
LCA of different building lifetime shearing layers for the allocation of green points
}

\author{
S. Pushkar \& O. Verbitsky \\ Department of Civil Engineering, Faculty of Engineering, \\ Ariel University, Israel
}

\begin{abstract}
Currently green-rating systems are mainly directed toward correctly sizing mechanical and electrical systems, which have short lifetime expectancies. In this case passive solar and bio-climatic architecture, which have long lifetime expectancies, are neglected. The main idea of this study is to realize a more consistent point allocation system for green building standards by using six shearing layers. The concept of shearing layers was invented by architect Frank Duffy and considers buildings as comprised of six different lifetime layers: Site, Structure, Skin, Services, Space, and Stuff, each reflecting distinct environmental damages. The objective of this study was to evaluate the six shearing layers using life cycle assessment (LCA). Six shearing layers of a simple generic basic module of a typical multi-story office building were evaluated using Eco-indicator 99 (EI99). A two-stage nested mixed balanced analysis of variance (ANOVA) test was used for comparison of the environmental performance of the building layers. It was found the environmental damage associated with building layers (Site, Structure, Skin) was higher than the environmental damage associated with Service layers (Services, Space, and Stuff). Using LCA permits green systems to more accurately handle the various environmental damages of buildings and building systems. As a result, a greater decrease in building-related ecological impacts can be achieved, thus encouraging sustainable building activities.
\end{abstract}

Keywords: rating systems, green building, sustainability, shearing layers concept, $L C A$. 


\section{Introduction}

Since 1980 much interest has been devoted to decreasing building-related environmental impacts and promoting sustainable building-related activities. Consequently, more than 40 green building rating systems were developed throughout the world (AlWaer et al [1]). All systems use a quite similar point assignment approach (Shaviv [2]). Shaviv called this point assignment approach as a "point hunting" approach that allows building owners and design teams to achieve "cheap and easy points". For example, there are many successfully certified green projects emphasizing the correct sizing of mechanical and electrical systems for efficiency (easier points to handle than designing truly sustainable architecture containing bio-climatic and passive solar aspects) (Shaviv [2]).

In this respect Shaviv [3] suggested that energy use associated with building design should be treated separately from the energy related to mechanical and hot water system design due to their different lifetime scales and subsequently, their different environmental damages (e.g., the lifetime of the building is 50100 years and the lifetime of the systems is 15-25 years). Shaviv suggested dividing the energy category of the Israeli Green Building Standard (SI5281) into two subcategories: "Building energy performance" and "Building services systems." This separation procedure is already embedded in the recent revision of SI5281 [4].

Furthermore, Pushkar and Shaviv [5] considered a building as six shearing layers (Site, Structure, Skin, Services, Space, and Stuff) based on the suggestion that each of the shearing layers reflects a different lifetime scale and therefore different environmental damages. Following this suggestion, the authors relocated green points to both the SI5281, Sustainable Building Tool (SBTool), and Leadership in Energy and Environmental Design (LEED) systems. According to Pushkar and Shaviv [5], "The division of the building to a six-layer concept will result in more reliable green points allocation." In this respect it is appropriate to briefly introduce the "shearing layers" concept.

The concept of shearing layers was invented by architect Frank Duffy. "The Shearing layers concept views buildings as a set of components that evolve in different timescales" [6]. The layers are: Site (timescale: site is eternal), Structure - the foundation and load-bearing elements (timescale: from thirty to three hundred years), Skin - exterior surfaces (timescale: twenty years), Services - communications wiring, electrical wiring, plumbing, fire sprinkler systems, HVAC, elevators and escalators (timescale: from seven to fifteen years), Space Plan - interior walls, ceilings, floors, and doors (timescale: three years) and Stuff - chairs, desks, phones, pictures; kitchen appliances, lamps, hairbrushes (timescale: from daily to monthly).

According to Pushkar and Shaviv [5] the visualization of a building as six shared layers (Site, Structure, Skin, Services, Space and Stuff) was derived from the suggestion that each of the sheared layers reflects a different lifetime scale and therefore different environmental damages. Based on this suggestion, the authors developed a method for the allocation of green points with accordance to 
the SI5281, Sustainable Building Tool (SBTool), and Leadership in Energy and Environmental Design (LEED) systems. It was concluded that applying the shearing layer concept to green systems will result in more reliable procedures for the allocation of green points.

However, "with the current push toward sustainable construction, LCA has gained importance as an objective method to evaluate the environmental impact of construction practices" (Singh et al. [7]). Thus, the LCA of the shearing layers should be evaluated prior to the allocation of green points. The objective of this study is to apply LCA methodology to evaluate the six shearing layers, Site, Structure, Skin, Services, Space, and Stuff, with a view toward developing a more reliable allocation of green points for green rating systems.

\section{Methods}

\subsection{Research framework}

A very simple generic basic module of a typical multi-story office building was used for the LCA evaluation of six shearing layers. LCA evaluations were performed on a $3 \mathrm{~m} \times 4 \mathrm{~m}$ and $3 \mathrm{~m}$ high module with three internal walls (partitions) and one external wall, located on a typical intermediate floor, between two similar modules. The module can face each of the four major orientations (north, west, south and east). For acclimatization energy calculations it was assumed that the building is constructed in a heating-dominated climate with a mild summer and cool winter (represented by Jerusalem's Typical Meteorological Year). Occupancy hours from Sunday to Thursday are 7:00 to 18:00. The reference point for the daylight calculation is at the module's center at a height of $0.8 \mathrm{~m}$ with a required luminance of $500 \mathrm{~lx}$. The air infiltration causes a $0.5 \mathrm{~h}^{-1}$ air change rate. Heating and cooling are by means of a heat pump (coefficient of performance (COP) for heating - 2.75 and for cooling - 3.0), with the set-points: $20^{\circ} \mathrm{C}$, and $24^{\circ} \mathrm{C}$, respectively. The design level for electric lights was $360 \mathrm{~W}$, for electric equipment $-250 \mathrm{~W}$, for occupants -1 person with activity level $100 \mathrm{~W}$. Clothing includes: winter $-1 \mathrm{Clo}$, summer $0.5 \mathrm{Clo}$. In addition, it should be noted that the minimum window area was $9 \%$ of the floor area $\left(1.08 \mathrm{~m}^{2}\right)$. The analysis was performed for a building's design life of 50 years.

Table 1 lists the components considered for each layer. Reinforced concrete technology was assumed. Table 2 lists the building materials considered for each of the building components: foundation, columns, beams, partitions, floor/ceiling, floor coverings, wall type, and wall coverings.

\subsection{Analysis tools and methods}

Thermal analysis was performed by EnergyPlus. Environmental Inventory analysis was performed by means of the SimaPro database tool. As outlined early, SimaPro is known as a mature database tool. It contains a comprehensive database of materials and processes in a variety of fields. In addition, all 
Table 1: Components of the six shearing layers.

\begin{tabular}{|l|l|}
\hline Building Layers & Components \\
\hline Site & Excavation and landfill \\
\hline Structure & Foundations, columns, beams, and ceilings \\
\hline Skin & $\begin{array}{l}\text { External walls, external wall covering, roof, } \\
\text { and glazing }\end{array}$ \\
\hline Service Layers & Components \\
\hline Services & $\begin{array}{l}\text { HVAC, electrical fixtures, and plumbing } \\
\text { fixtures }\end{array}$ \\
\hline Space Plan & Partitions, floor coverings, and doors \\
\hline Stuff & Computers, printers, furniture, and lamps \\
\hline
\end{tabular}

Table 2: Description of building components.

\begin{tabular}{|l|l|}
\hline Component & $\begin{array}{l}\text { Composite materials (thickness }(\mathrm{m})) / \\
(\text { section }(\mathrm{m} \times \mathrm{m}))\end{array}$ \\
\hline Foundation: concrete & Length: $14,(0.4 \times 0.5)$, steel \\
\hline Columns: concrete & Length: $2.6(0.3 \times 0.3)$ \\
\hline Beams: concrete & Length: $6,(0.2 \times 0.35)$, steel \\
\hline Roof/ceiling: concrete slab & Reinforced concrete $(0.14)$ \\
\hline Roof/ceiling: concrete slab & Reinforced concrete $(0.14)$ \\
\hline Wall type: concrete & $\begin{array}{l}\text { Concrete }(0.05), \text { polystyrene }(0.03), \text { concrete } \\
(0.15)\end{array}$ \\
\hline Wall coverings: stone & Stone $(0.02)$, concrete $(0.05)$, mortar $(0.006)$ \\
\hline Partitions: gypsum board & $\begin{array}{l}\text { Gypsum board }(0.0125), \text { glass wool }(0.075), \\
\text { gypsum board }(0.0125)\end{array}$ \\
\hline Floor coverings: marble & Sand $(0.06)$, mortar $(0.02)$, marble $(0.012)$ \\
\hline
\end{tabular}

processes are editable and can be changed to fit different conditions, or to build new ones. Environmental scoring was established by means of the EI99 tool. Due to its comprehensive set of currently utilized methodological options, EI99 was found as a suitable LCA tool when it is desired to derive a general and methodology-independent conclusion regarding the environmental damages.

Initially, the Eco-Indicator 99 (EI99) tool [8] was used to calculate the environmental scores $(\mathrm{Pt})$ associated with the six shearing building layers. As a result, six EI99 environmental scores (e/e, e/a, h/h, h/a, i/i, and i/a options) were calculated for each studied layer (Site, Structure, Skin, Service, Space Plan, and Stuff). Then, these layers were compared by applying a two-stage nested mixed balanced ANOVA test.

\subsection{LCA of shearing layers}

Architect Frank Duffy considered the site layer as a building layer with "eternal" timescale. However, in practice, green rating systems usually consider a list of site-relevant credits. For example, the SI5281 lists the following site credits: site 
selection, contaminated land, density for building and development, heat island effect, maximizing the usages of built space, conservation of local fertile/top soil for use on site, and ecology on site [4]. The building module considered in this study is supposed to be located within a brownfield site. As a result, in this study only remediation practices (excavation and landfilling) were considered under the Site layer. A minimum transportation distance of $50 \mathrm{~km}$ was assumed from the building site to a disposal site.

The Structure (foundation and load-bearing elements) was considered by Duffy as a layer with a timescale of fifty to three hundred years. In this_study the Structure layer included the foundations, columns, beams, and ceilings. In Israel, the load-bearing building components are usually constructed with reinforced concrete technologies. The environmental evaluations were conducted for all components of the Structure layer for two life cycle stages: production and construction (P\&C) and maintenance and demolition (MtoD). Because the timescale of the Structure layer (50 years) and the life cycle of the whole building were the same, only the demolition portion of MtoD was taken into account. In addition, due to the negligible influence of the properties of Structure-layer materials on the environmental damage associated with the thermal acclimatization, ventilation, and lighting of buildings, the operational energy stage (OE) was neglected.

The Skin layer (exterior surfaces) was considered by Duffy as a layer with a timescale of twenty to fifty years. In this study the Skin layer included the external wall (including insulation layer), external wall covering, roof, roof covering, and glazing (Table 1). Environmental evaluations were conducted for all components of the Skin layer for three life cycle stages: P\&C, OE, and MtoD. The MtoD stage of the Skin layer, in addition to demolition, also included the maintenance procedures. Thus, data on environmental damage from cleaning, repair, complete replacement of a component, recycling practices, and demolition should be considered. Only demolition procedures were considered in the present study. The timescale of stonewall coverings is as long as the entire lifetime of the building. Therefore, this component was only destroyed (without replacement) at the end-of-life stage of the building. The operational energy performance of HVAC for thermal acclimatization, ventilation, and lighting of buildings depends on the properties of materials used in the building envelope. This required consideration of the OE stage for the Skin layer.

The Services layer (communication wiring, electrical wiring, plumbing, fire sprinkler systems, HVAC, elevators, and escalators) was considered by Duffy as a layer with a timescale of ten to twenty years. In this study, the Services layer included HVAC, electrical fixtures, and plumbing fixtures. Environmental evaluations were conducted for the $\mathrm{P} \& \mathrm{C}$ and MtoD stages. The service life of the electrical and plumbing fixtures was assumed to be 10 years.

The Space Plan layer (interior walls, ceilings, floors, and doors) was considered by Duffy as a layer with a timescale of three to ten years. In this study, the Space Plan layer included partitions, floor coverings, and doors. Environmental evaluations were conducted for all components of the Space Plan layer for two life cycle stages: P\&C and MtoD. The MtoD stage of this layer, in 
addition to demolition, also included the maintenance procedures. Thus, data on environmental damage from cleaning, repair, complete replacement of a component, recycling practices, and demolition should be considered. Only cleaning and demolition procedures were considered in the present study. For example, the floor coverings in office buildings should be cleaned every day of the workweek. Thus, a cleaning rate of 240 times per year was used as an appropriate cleaning rate for the building floor coverings. The timescale of marble floor coverings is as long as the entire lifetime of the building. Therefore, this component was only destroyed (without replacement) at the end-of-life stage of the building.

The Stuff layer (chairs, desks, phones, pictures, kitchen appliances, lamps, and hairbrushes) was considered by Duffy as a layer with a timescale of days to months. In this study the Stuff layer included computers, prints, furniture, and lamps. Environmental evaluations were conducted for all components of the Stuff layer for two life cycle stages: P\&C and MtoD. In contrast to the daily to monthly timescale suggested by Duffy, in this study a more reliable service life of 5 years for the Stuff layer was considered.

\subsection{A statistical terminology and sampling design}

In the present study, some statistical terminology (i.e., a "sampling frame", a "primary unit", "sub-units", and "individual sub-units") presented by Picquelle and Mier [9] was used. The sampling frame is defined as a "collection of all elements (primary sampling units) accessible for sampling in the population of interest". The primary unit is defined as an "element within the sampling frame that is sampled and is statistically independent of other sampling units within frame". The primary unit contains the "sub-units". The sub-unit contains the "individual sub-units" [9].

Consequently, in the one-stage sampling design, the sampling frame contains a number of the primary units. The primary unit does not contain the sub-units. Measurements are taken on the primary units. In the two-stage sampling design, the sampling frame contains a number of the primary units. However, in contrast to the one-stage sampling design, in this case the primary unit contains the subunits. The sub-unit also contains a number of individual sub-units. Measurements are taken on individual sub-units.

The sampling frame is separated into factors of interest. In the present study, a two-stage sampling design with a two-stage factor of interest was used. The first stage refers to two levels for the primary sampling unit fixed factor of interest (A). The second stage refers to two levels for the sub-unit random factor of interest (B). The factor of interest B nested within each primary sampling unit factor of interest A (denoted by B(A)).

In the two-stage sampling design, the building industry is defined within a sampling frame under two sets of methodological options: (i) the options with their particular weighting set (e/e, i/i, and $\mathrm{h} / \mathrm{h}$ - individual sub-units) and the options with the set of average weighting set (e/a, i/a, and $\mathrm{h} / \mathrm{a}$ - individual subunits). Those two sets of options are included in the environmental EI99 evaluation (primary sampling unit). Consequently, the difference between any 
two building layers (i.e., factor of interest A) can be evaluated within the single sampling frame, where six methodological options are statistically pooled and statistical analysis is simultaneously performed. In this context, the appropriate statistical test is a two-stage nested mixed balanced ANOVA test.

There are three null hypotheses:

(i) There are no differences in effects between primary sampling units in a two-stage sampling design when the building layers (Site, Structure, and Skin) and Services layers (Services, Space plan, and Stuff) are considered.

(ii) There are no differences in effects between the primary sampling units when only the building layers are considered.

(iii) There are no differences in effects between primary sampling units when only the Service layers are considered.

\subsection{Statistical analyses}

The data sets were log-transformed prior to analysis. A two-stage nested mixed balanced ANOVA test was used to compute the difference between all pairings of building layers within the primary sampling units.

Neo-Fisherian significance assessments were used to interpret the signs and magnitudes of the statistical effects. The P-values were evaluated according to three-valued logic: "it seems to be positive" (i.e., there seems to be a building layer difference), "it seems to be negative" (i.e., there does not seem to be a building layer difference), and "judgment is suspended" regarding the building layer difference [10].

\section{Results}

The analyzed building layers and Service layers were evaluated by EI99 for a very simple generic basic module of a typical multi-story office building, when applying all of the methodological options $(\mathrm{h} / \mathrm{h}, \mathrm{h} / \mathrm{a}, \mathrm{i} / \mathrm{i}, \mathrm{i} / \mathrm{a}, \mathrm{e} / \mathrm{e}$, and e/a). Only the results associated with $\mathrm{h} / \mathrm{a}$ methodological option are presented in Figure 1. However, under all methodological options, the environmental damage associated with building layers was higher than the environmental damage associated with Service layers. The environmental damage associated with Skin was higher than the environmental damage associated with both Site and Structure. The environmental damage associated with Structure was higher than the environmental damage associated with Site.

Table 3 shows a comparison between the two types of layers, building layers and service layers, evaluated with the two-stage nested mixed balanced ANOVA test. The differences between the pairing building layers and service layers seem to be positive.

Table 4 shows the P-values as a result of the environmental damage comparison in any of the pairings within three building layers evaluated with the two-stage nested mixed balanced ANOVA test. The differences between the pairings Site and Structure, Site and Skin, and Structure and Skin seem to be positive. 


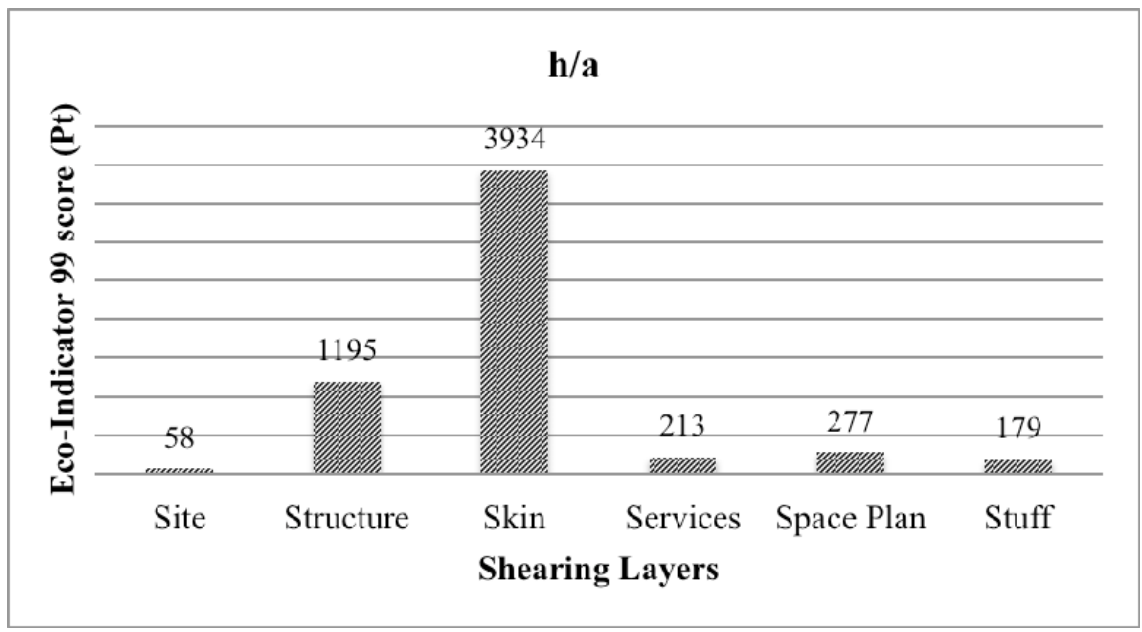

Figure 1: Environmental damage resulting from the building and service layers.

Table 3: P-value (P) of the difference between the two types of layers, Building layers and Service layers as a function of the environmental damage.

\begin{tabular}{|c|c|}
\hline Type of layers & $\begin{array}{c}\text { Service layers (Services + Space plan } \\
+ \text { Stuff) }\end{array}$ \\
\hline $\begin{array}{c}\text { Building layers (Site + Structure }+ \\
\text { Skin) }\end{array}$ & 0.0024 \\
\hline
\end{tabular}

Note: Two-stage nested mixed (i.e., two levels for the primary sampling unit fixed factor (A) and two levels for the subunit random Factor B) balanced ANOVA test is used. Degree of freedom (df) is presented as $\mathrm{dfA}=1$ (numerator degree of freedom) $\mathrm{dfB}=2$ (denominator degree of freedom). The P-value is the probability resulting from significance testing.

Table 4: P-value (P) of the pairings difference in the three building layers (Site, Structure, and Skin) as a function of the environmental damage.

\begin{tabular}{|l|l|l|l|}
\hline Building layers & Site & Structure & Skin \\
\hline Site & $\mathrm{X}$ & 0.0009 & 0.0002 \\
\hline Structure & & $\mathrm{X}$ & 0.0062 \\
\hline Skin & & & $\mathrm{X}$ \\
\hline
\end{tabular}

Note: Two-stage nested mixed (i.e., two levels for the primary sampling unit fixed factor (A) and two levels for the subunit random Factor B) balanced ANOVA test is used. Degree of freedom (df) is presented as $\mathrm{dfA}=1$ (numerator degree of freedom) $\mathrm{dfB}=2$ (denominator degree of freedom). The P-value is the probability resulting from significance testing. 
Table 5 shows the P-values as a result of the environmental damage comparison in any of the pairings within the three Service layers evaluated with the two-stage nested mixed balanced ANOVA test. The differences between the pairing Services and Space Plan seem to be negative. Regarding the difference between the pairing Services and Stuff and between the pairing Space Plan and Stuff, judgment is suspended.

Table 5: P-value (P) of the pairings difference in the three Service layers (Site, Structure, and Skin) as a function of the environmental damage.

\begin{tabular}{|l|l|l|l|}
\hline Building layers & Site & Structure & Skin \\
\hline Site & $\mathrm{X}$ & 0.0009 & 0.0002 \\
\hline Structure & & $\mathrm{X}$ & 0.0062 \\
\hline Skin & & & $\mathrm{X}$ \\
\hline
\end{tabular}

Note: Two-stage nested mixed (i.e., two levels for the primary sampling unit fixed factor (A) and two levels for the subunit random Factor B) balanced ANOVA test is used. Degree of freedom (df) is presented as $\mathrm{dfA}=1$ (numerator degree of freedom) $\mathrm{dfB}=2$ (denominator degree of freedom). The P-value is the probability resulting from significance testing.

\section{Discussion}

Currently, the principal problem with green rating systems is that they consider both building- and system-related credits without separating them according to their lifetime expectancies and different environmental damages (Shaviv 2008). Thus, Pushkar and Shaviv [5] suggested adopting the shearing layer concept in several well-known green rating systems, including SI5281, SBTool, and LEED. Buildings were divided into six shearing layers, i.e., Site, Structure, Skin, Services, Space plan, and Stuff, according to the layers' different lifetime expectancies and scales, which determine their different environmental damages [5]. However, allocations of green points were performed without considering the LCA of the shearing layers.

Some green building rating systems have begun to recognize the importance of including building component lifetime expectancies in LCA applications. For example, the Material category in the BRE Environmental Assessment Method (BREEAM) includes credit for the life cycle effects of external walls, windows, roof, upper floor slabs, and floor finishes/coverings [11]. Leadership in Energy and Environmental Design (LEED) offers a "building life-cycle impact reduction" credit for their Material category [12].

This paper presents the application of the six methodological options $(\mathrm{i} / \mathrm{i}, \mathrm{h} / \mathrm{h}$, e/e, i/a, h/a, and e/a) of EI99 to six shearing layers, i.e., Site, Structure, Skin, Services, Space plan, and Stuff, for a more reliable point allocation for green rating systems. Under six methodological options (performed simultaneously with environmental evaluations), the building layers have higher priority (approximately 90\%) than the Service layers (approximately 10\%). 
In this work, it was demonstrated the ratio of the comparison of the environmental damages among three building layers (Site, Structure, and Skin) can be represented as approximately 1:25: 65 (Figure 1), thereby confirming that Skin is the most important layer. This is because environmental evaluations of this layer were conducted for the $\mathrm{OE}$ stage in addition to the $\mathrm{P} \& \mathrm{C}$ and $\mathrm{MtoD}$ stages. In contrast, the Site layer has a lower priority. In addition, the results obtained in this work revealed a ratio of 2: 1: 1 for System, Space plan, and Stuff layers, respectively (Figure 1).

An incorrect green point allocation in building rating systems can lead to the application of incorrect sustainable strategies in subsequent projects. This can result in different environmental damage than expected, thereby requiring distinctly different cost-effective solutions. This result can lead to incorrect estimates of the initial construction cost, the life-cycle cost, the embodied energy, occupants' health, resource/habitat conservation, among other variables, of a building throughout its life cycle phases: production, construction, operation, maintenance, demolition, and rehabilitation.

According to Pushkar and Shaviv [5] a more reliable credit allocation of green points for green building standards may be achieved using six different lifetime shearing layers: Site, Structure, Skin, Services, Space, and Stuff, each reflecting distinct environmental damages. The primary goal of the study was to suggest an LCA framework application for the environmental evaluation of the six aforementioned shearing layers. Further environmental studies in this area are required to continue improving LCA of the six layers for the allocation of green points.

\section{References}

[1] AlWaer, H., Sibley, M. \& Lewis, J., Different stakeholder perceptions of sustainability assessment. Architectural science review, 51(1), pp. 48-49, 2008.

[2] Shaviv, E., Applications of simulation and CAD tools in the Israeli "Green Building" Standard for achieving low energy architecture. Proc. of Building Simulation 2011: 12th Conference of International Building Performance Simulation Association, Sydney, 14-16 Nov, 2011.

[3] Shaviv, E., Passive and Low Energy Architecture (PLEA) VS Green Architecture (LEED). PLEA 2008 - 25th Conference on Passive and Low Energy Architecture, Paper No 371 Dublin, 22nd to 24th Oct, 2008.

[4] SI5281-3 Sustainable Buildings ("Green Buildings"), Parts 3: Requirements for Office Buildings. The Standards Institution of Israel, 2011.

[5] Pushkar, S. \& Shaviv, E., Green rating systems: an adoption of shearing layer concept. Proc. of SB13 Oulu, eds. Finnish Association of Civil engineers RIL VTT Technical Research Centre of Finland, pp. 86-88. Finland: Oulu, 2013

[6] Brand, S., How Buildings Learn. Viking. New York, 1994. 
[7] Singh, A., Berghorn, G., Joshi, S., \& Syal, M. Review of Life-Cycle Assessment Applications in Building Construction. Journal of Architectural Engineering, 17(1), pp. 15-23, 2011.

[8] Goedkoop, M. \& Spriensma, R. The Eco-indicator 99, A damage oriented method for life cycle impact assessment." PRé Consultants B.V., Plotterweg 12, 3821 BB Amersfoort, 2001.

[9] Picquelle, S.J., \& Mier, K.J., A practical guide to statistical methods for comparing means from two-stage sampling. Fisheries Research, 107, pp. 113, 2011.

[10] Hurlbert, S.H. \& Lombardi, C.M, Lopsided reasoning on lopsided tests and multiple comparisons. Australian \& New Zealand Journal of Statistics, 54, pp. 23-42, 2012.

[11] BREEAM, BREEAM New Construction, Technical Manual, Accessed September 15, 2012.

[12] LEED, LEED for New Construction \& Major Renovations, http://www.leeduser.com/leed-credits, 2011. 